\title{
Correspondência de Julio Porto-Carrero a Arthur Ramos: a Sociedade Brasileira de Psicanálise e a preocupação com a tradução dos termos psicanalíticos, décadas de 1920 e 1930
}

\author{
Correspondence from Julio Porto-Carrero to Arthur Ramos: \\ the Brazilian Psychoanalytic Society and concern over the \\ translation of psychoanalytic terms in the 1920s and 1930s
}

Rafael Dias de Castro

Professor, Universidade do Estado de Minas Gerais.

Praça dos Estudantes, 23

36800-000 - Carangola - MG -

Brasil

castro_rd@yahoo.com.br
CASTRO, Rafael Dias de. Correspondência de Julio Porto-Carrero a Arthur Ramos: a Sociedade Brasileira de Psicanálise e a preocupação com a tradução dos termos psicanalíticos, décadas de 1920 e 1930. História, Ciências, Saúde-Manguinhos, Rio de Janeiro, v.24, n.4, out.-dez. 2015, p.1451-1465.

Resumo

O objetivo deste artigo é apresentar uma correspondência enviada em 1932 pelo psiquiatra Julio Porto-Carrero ao psiquiatra Arthur Ramos, informando sobre as atividades da Sociedade Brasileira de Psicanálise e a preocupação em sistematizar alguns conceitos psicanalíticos para sua tradução na língua portuguesa. Por meio dessa correspondência, juntamente com a análise de outras fontes, pretende-se mostrar como os psiquiatras-psicanalistas cariocas buscavam incluir a psicanálise no meio médico-científico do período, procurando estimular um número cada vez maior de especialistas a se interessar pela teoria de Freud no país.

Palavras-chave: história da psicanálise; história da psiquiatria; Rio de Janeiro; Julio Porto-Carrero (1887-1937); Arthur Ramos (1903-1949).

\section{Abstract}

The article presents the correspondence that psychiatrist Julio Porto-Carrero sent to psychiatrist Arthur Ramos in 1932 to inform him about the activities of the Brazilian Psychoanalytic Society and about a concern over systematizing the translation of certain psychoanalytic concepts into Portuguese. This correspondence is used in conjunction with the analysis of other sources to suggest that psychiatrists and psychoanalysts in Rio de Janeiro were then endeavoring to make a place for psychoanalysis in the day's medical and scientific circles and encourage ever more specialists in Brazil to take an interest in Freud's theory.

Keywords: history of psychoanalysis; history of psychiatry; Rio de Janeiro; Julio Porto-Carrero (1887-1937); Arthur Ramos (1903-1949).

http://dx.doi.org/10.1590/S0104-59702015000400014 
A presentamos aqui uma correspondência enviada em 1932 por Julio Porto-Carrero, ${ }^{1}$ importante psiquiatra-psicanalista carioca das décadas de 1920 e 1930, a Arthur Ramos, ${ }^{2}$ psiquiatra baiano que se mudou para o Rio de Janeiro em 1934 e passou a dirigir a Seção Técnica de Ortofrenia e Higiene Mental do Departamento de Educação e Cultura do Distrito Federal, se apropriando da psicanálise em muitos casos analisados (Castro, 2014). Nessa carta, o objetivo principal de Porto-Carrero era informar Ramos sobre as atividades da Sociedade Brasileira de Psicanálise e a preocupação em sistematizar alguns conceitos psicanalíticos para sua tradução na língua portuguesa.

A importância da divulgação de tal fonte se deve a múltiplos fatores, relacionados principalmente com a história da psicanálise no Brasil, a história da psiquiatria no Rio de Janeiro e o debate mais amplo sobre a circulação de conhecimentos científicos em contextos periféricos (Figueirôa, 1998). Em primeiro lugar, a importância da divulgação de tal correspondência se deve ao fato de que alguns dos psiquiatras-psicanalistas das décadas de 1920 e 1930 foram os responsáveis pelas primeiras traduções dos textos freudianos. A carta em questão nos mostra não somente a busca da divulgação de tal saber no país, como também a preocupação com que fossem disseminados os conceitos de maneira condizente com os "textos originais" de Freud. Outro ponto importante é que parte da historiografia informa que a primeira Sociedade Brasileira de Psicanálise, fundada em 1927, havia terminado suas atividades em 1929, fato que a correspondência nos aponta não ser verdadeiro. Além disso, não se sabia, até então, que a sede da Sociedade havia se transferido de São Paulo para o Rio de Janeiro em 1928, o que foi comprovado por tal carta e também por outras fontes debatidas neste texto. Por fim, a constatação da busca de institucionalização da psicanálise no contexto científico carioca também é relevante, e essa correspondência nos mostra alguns movimentos realizados por tais psiquiatras no sentido de ampliar sua inserção no meio médico e acadêmico carioca do período.

A correspondência ora em análise foi localizada nos arquivos manuscritos da Biblioteca Nacional (Rio de Janeiro, RJ), organizados no fundo intitulado "Coleção Arthur Ramos". De acordo com Vera Faillace (2004, p.7), a coleção compõe o acervo vendido parcialmente à Biblioteca Nacional em 1956, "parte pela viúva, Luiza Ramos, parte pela Universidade do Brasil. Contém correspondências do titular e de terceiros, recortes de jornais, folhetos, fotografias, originais manuscritos". ${ }^{3}$ Consideramos que a divulgação e a análise de tal correspondência, juntamente com outras aqui debatidas e que fazem parte da mesma coleção, são relevantes porque tornam mais conhecido tal acervo e sua rica diversidade de fontes, oferecendo ao pesquisador interessado maior aprofundamento nas discussões sobre a história da psiquiatria no país e a relação entre seus atores. Além disso, há que ressaltar o fato de que existem poucas correspondências conhecidas trocadas entre os psiquiatras da época, pois os acervos institucionais e/ou privados e os acervos pessoais ou não estão organizados, como é o caso da documentação do médico Juliano Moreira (Venancio, 2005), e/ou são restritos em sua dimensão documental e distribuídos em diversos arquivos (Fiocruz, 2004). 


\section{A Sociedade Brasileira de Psicanálise: 1927-1928}

Entre as décadas de 1910 e 1940, a psicanálise foi apropriada por uma "geração" de psiquiatras como uma importante ferramenta para trazer novas respostas ao problema da identidade nacional (Castro, 2014). De acordo com essas leituras, se ao brasileiro faltava iniciativa e ideais a seguir, se sua sexualidade exacerbada era reflexo de seu comportamento "primitivo" e se a prostituição, o crime, as doenças venéreas e taras degenerativas estavam presentes na maior parte do território brasileiro, os psiquiatras, com auxílio da ferramenta psicanalítica, poderiam intervir: era necessário educar o brasileiro, fazendo evoluir seu id, moldando seu ego à civilização. O psicodiagnóstico do brasileiro como um "id primitivo" tornava-o apto a receber o projeto a que então se propunha: se as manifestações comportamentais brutas, sem controle e/ou condução, eram consequência do primitivismo dos brasileiros, tornavase necessário combater as degenerações provenientes de seu abandono pelo Estado e pela educação familiar e da escola (o alcoolismo e os desvios de conduta, por exemplo), por meio da implementação de condições educativas favoráveis ao seu desenvolvimento "interior", da "civilização" de seu ego (Castro, 2014).

Para tanto, esses atores fizeram da ferramenta psicanalítica uma prática científica institucionalizada. Foi assim que surgiram, nas décadas de 1920 e 1930, a Clínica de Psicanálise dentro da Liga Brasileira de Higiene Mental (1926), a inserção da psicanálise na Associação Brasileira de Educação (a partir de 1927), a criação da Sociedade Brasileira de Psicanálise (1927-1928) e a especialização em psicanálise dentro da Faculdade de Medicina da Universidade do Rio de Janeiro (1931). Nesses espaços científicos foi possível organizar toda uma "metapsicologia ortopédica" para instruir os brasileiros a moldar seus comportamentos, educar seus filhos e aprender como "descarregar" seus impulsos no ambiente com o mínimo de prejuízo para a sociedade (e, de preferência, em seu benefício).

Nesse contexto, no dia 24 de novembro de 1927 realizava-se na cidade de São Paulo a sessão de fundação da Sociedade Brasileira de Psicanálise, a primeira da América Latina (Ponte, 1999, p.72). Tal sociedade congregava escritores, jornalistas, artistas plásticos, médicos e professores, que buscavam, com base em referências bastante distintas entre si, novos modos de compreensão da realidade social (Facchinetti, 2001, p.95). Inscreveram-se como membros na primeira reunião:

Prof. dr. Franco da Rocha [psiquiatra], Prof. Raul Briquet [professor de obstetrícia], prof. dr. Flamínio Fávero [professor de medicina legal], prof. dr. Antonio de Sampaio Dória [político, jurista e educador], drs. F. Marcondes Vieira, James Ferraz Alvim [psiquiatra], José Lopez Ferraz [político], Menotti Del Picchia [escritor], Nestor Solano Pereira [médico leprologista], César Martinez, Thomé Alvarenga, Fausto Guerner [médico neurologista], Getúlio de Paula Santos [médico], Samuel L. Ribeiro [médico sanitarista], Maurício Pereira Lima [médico], Pedro de Alcântara [médico pediatra], Cândido Motta Filho [jornalista, advogado, juiz de paz], Antônio Roldão Lopes de Barros [médico, advogado, educador], Wladimir Kehl [inspetor médico escolar], Osório César [psiquiatra, médico do hospital do Juqueri], Antônio Paim Vieira [médico, artista plástico], Antônio Ferreira de Almeida Junior [médico, advogado, educador], Lourenço Filho [educador], Durval Marcondes [psiquiatra, escritor] (Noticiário, 1928, p.109). 
Foram eleitos para a primeira diretoria da sociedade: presidente - Franco da Rocha; vice-presidente - Raul Briquet; secretário - Durval Marcondes; tesoureiro - Lourenço Filho (Noticiário, 1928, p.110). De acordo com Durval Marcondes, ${ }^{4}$ o surgimento da sociedade se dava porque, no Brasil,

fala-se muito de psicanálise, chegando-se até mesmo a atacá-la sem ter dela uma experiência suficiente ... Seria oportuna a formação de uma sociedade que fosse um centro coordenador dos estudos com foco de propaganda das ideias de Freud (citado em Noticiário, 1928, p.109).

O psiquiatra Franco da Rocha ${ }^{5}$ acrescentava: "Já é bem tempo de se fazer uma propaganda mais intensa dos princípios psicanalíticos nas suas múltiplas aplicações, devendo-se procurar interessar, sobretudo, a classe dos professores" (citado em Noticiário, 1928, p.109).

No ano seguinte à fundação da Sociedade, seria lançado o primeiro número da Revista Brasileira de Psicanálise. Em sua apresentação, assegurava-se como função "divulgar a teoria freudiana nos nossos meios científicos e, o que não é de somenos, defendê-la das deturpações a que infelizmente está sujeita" (Editorial, 1928, p.5). Além disso, a revista pretendia ser para os psicanalistas brasileiros "um centro coordenador dos esforços e por cujo intermédio poderão contribuir eficientemente para o desenvolvimento da doutrina" (p.5). Esse seria o único número da revista lançado pela Sociedade, não chegando a ser, assim, um centro aglutinador dos psicanalistas brasileiros.

O surgimento da Revista Brasileira de Psicanálise não passou despercebido por Sigmund Freud, que recebeu de Durval Marcondes e Porto-Carrero um exemplar do primeiro número e informações sobre tal publicação. Respondendo a Durval Marcondes, Freud afirmou:

A visão da Revista Brasileira de Psicanálise me deu muito prazer. Que ela tenha um futuro próspero. O efeito seguinte deste envio foi que eu comprei uma pequena gramática portuguesa e um dicionário alemão-português. Durante as férias eu quero chegar ao ponto de poder ler pessoalmente a revista (citado em Nosek et al., 1994, p.89).

Para Porto-Carrero, a resposta chegaria com a mesma intenção descrita a Marcondes:

Sob a influência das suas notícias e a publicação da Revista Brasileira, comecei a aprender português. Espero logo conseguir ler, mas será uma leitura muda, pois tudo o que intuo sobre a pronúncia me parece assustadoramente difícil. Minha intenção é apenas poder compreender o que está sendo publicado na revista (citado em Lago, 16 ago. 2011).

Entretanto, Freud não chegaria a compreender a língua portuguesa conforme almejado. Em carta enviada a Arthur Ramos, quatro anos mais tarde, Freud (1 jun. 1932) agradecia o envio de trabalhos do autor (não chega a citar quais) afirmando: "Fico feliz pela remessa dos trabalhos, porém com muito pesar, pois não entendo o conteúdo do interessante trabalho". Muitos dos trabalhos seriam enviados a Freud em português, mas na maioria das vezes as cartas seriam escritas em inglês ou francês. ${ }^{6}$

Um mês após o lançamento da revista, seria dado um novo passo importante com a fundação de uma seção da Sociedade Brasileira de Psicanálise no Rio de Janeiro:

A convite da Sociedade Brasileira de Psicanálise de São Paulo, reuniram-se no Hospital Nacional de Psicopatas alguns psicanalistas desta capital [Rio de Janeiro], sob a 
presidência do prof. Juliano Moreira, para fundar um núcleo de estudos de psicanálise em conexão com aquela sociedade (Editorial, 6 jul. 1928, p.5).

Com a fundação do núcleo do Rio de Janeiro, a proposta estabelecida, levada por Durval Marcondes, delimitava as seguintes bases para o funcionamento da Sociedade como um todo:

(1) A sociedade Brasileira de Psicanálise terá sede no Rio de Janeiro e será dividida em seções nos vários estados do Brasil. (2) Como traço de união, haverá um presidente geral, renovável de dois em dois anos, uma revista que será a continuação da Revista Brasileira de Psicanálise, cujo primeiro número já foi publicado pela referida Sociedade fundada em São Paulo. (3) Cada seção terá um presidente regional e será autônoma na sua organização e direção interna. (4) A organização da revista será feita na sede, para onde será remetido todo o material a publicar. (5) No caso de ser impressa a revista fora da sede, o secretário da seção onde foi feita a impressão será encarregado da impressão. 6. Da mensalidade, cada seção destinará certa quantia, a mesma para todas as seções, para o custeio da publicação da revista (Editorial, 6 jul. 1928, p.5).

Como se pode notar, a Sociedade Brasileira de Psicanálise, criada em São Paulo em 1927, não somente fundou um núcleo no Rio de Janeiro em 1928, como também transferiu sua sede para esta cidade. Apesar disso, por sugestão do próprio Juliano Moreira, "foi aclamado o professor Franco da Rocha para ser o presidente geral da Sociedade Brasileira de Psicanálise, de acordo com as bases estabelecidas" (Editorial, 6 jul. 1928, p.5). Nessa reunião seriam declarados Juliano Moreira, como presidente, e Porto-Carrero, como vice-presidente da seção do Rio de Janeiro.

Uma das primeiras iniciativas da Sociedade, assim estabelecida, foi comunicar ao próprio Freud sua fundação. Em resposta a Durval Marcondes, Freud enviaria uma carta com os seguintes dizeres:

Prezado colega, agradeço imensamente seu minucioso relatório sobre os acontecimentos esperançosos no seu país. dr. Porto-Carrero também me escreveu a respeito, e eu repito ao senhor o pedido que enderecei a ele. Gostaria que os senhores elaborassem em conjunto uma exposição sobre essas ocorrências, destinada à Revista Internacional de Psicanálise, e a enviassem ao presidente dr. Eitingon, para que assim o interesse para nosso novo grupo brasileiro possa ser despertado (citado em Nosek et al., 1994, p.90).

A carta de Freud enviada a Porto-Carrero trazia de fato o mesmo pedido, contudo continha mais alguns detalhes:

Quão notável que no distante Brasil nasça de repente um movimento psicanalítico pronto, com divulgação em toda a sociedade e naturalmente também alguma oposição. Esta última não deve faltar. Alegra-me que o senhor reconheça sua necessidade. É como na técnica analítica. Sem a superação de obstáculos, não existe sucesso. E agora um pedido fundamental. É de grande importância para mim que sua Sociedade logo se sinta em casa na Sociedade Internacional e que esta acompanhe o que ocorre no Brasil. Para esse fim, nada pode contribuir melhor do que o senhor redigir um relatório para a Revista, que contenha aproximadamente aquilo que consta das cartas suas e do dr. Durval Marcondes, como a história da fundação da sua Sociedade, o relacionamento entre os grupos do Rio e de São Paulo e sobre os seus esforços na Sociedade. O relatório deve ser enviado ao nosso presidente, dr. Max Eitingon (citado em Lago, 16 ago. 2011). 
Após as trocas de cartas com Freud e Eitingon, a Sociedade Brasileira de Psicanálise foi reconhecida pela International Psychoanalitic Association (IPA) como Study Group em 1929. No ano seguinte, Eitingon escreveu para o grupo novamente, pedindo que este buscasse se organizar nos moldes definidos pelo Congresso de Bad-Homburg de $1925 .{ }^{7}$ Entretanto, esse pedido veio num período de significativas mudanças no contexto psiquiátrico brasileiro. Juliano Moreira perdera seus cargos de direção do Hospício Nacional de Alienados e de diretor-geral de Assistência a Alienados, em 1930, sendo aposentado compulsoriamente (Pacheco e Silva, 2009). Franco da Rocha, em São Paulo, já tinha também se aposentado (Sagawa, 1992, p.83). Com a saída dos presidentes das duas seções da Sociedade, produziuse uma crise no jovem Study Group. Enquanto os poucos membros de São Paulo achavam que o reconhecimento de sua sociedade pela IPA era fundamental para a sua sobrevivência, o grupo do Rio de Janeiro, utilizando a psicanálise como ferramenta da ciência psiquiátrica, ficou pouco propenso a seguir as orientações da IPA (Facchinetti, 2001, p.153). Em meio ao conflito, as duas seções se separaram. Apesar de parte da historiografia afirmar que Durval Marcondes teria fechado a Sociedade e buscado os meios para trazer didatas estrangeiros para reabri-la nos moldes da IPA (Perestrello, 1992, p.116; Ponte, 1999, p.75), a sede no Rio continuou a funcionar de acordo com os objetivos iniciais de promoção da psicanálise por meio de palestras e cursos de divulgação, além da tarefa de tradução de trabalhos advindos das Obras completas de Freud.

Os encontros permaneciam acontecendo dentro do Hospital Nacional de Psicopatas e, na maioria das vezes, eram anunciados nos jornais. Ainda em 1930, anunciava-se uma reunião "da Sociedade Brasileira de Psicanálise dia 12 de maio, às 10 horas da manhã no Hospital Nacional de Psicopatas" (Editorial, 11 maio 1930, p.2). A Sociedade ainda buscava inserir em suas fileiras membros interessados no desenvolvimento e na consolidação da doutrina de Freud no meio científico brasileiro. Essa perspectiva fica evidente em cartas trocadas por Porto-Carrero e Arthur Ramos entre 1929 e 1932.

\section{Correspondência entre Porto-Carrero e Arthur Ramos}

Arthur Ramos já vinha desenvolvendo trabalhos ligados à psicanálise na Bahia (Ramos, jan. 1933) e, por isso, recebeu, em 1929, o seguinte convite de Porto-Carrero: "Na minha carta anterior pedia-lhe e aqui renovo o pedido - que aderisse à Sociedade Brasileira de Psicanálise, que, fundada há dois anos em São Paulo, se transferiu para aqui no ano passado, ficando São Paulo como Departamento Paulista" (Porto-Carrero, 8 abr. 1929). A intenção expressa na carta não era somente para a filiação de Arthur Ramos à Sociedade, mas também que "um dia tenhamos o Departamento Bahiano, quando forem vencidas as dificuldades e resistências que a psicanálise sempre encontra, de começo" (Porto-Carrero, 8 abr. 1929).

O contato prosseguiria entre Porto-Carrero e Arthur Ramos, que permanecia residente no estado da Bahia. Em carta enviada em 1932, Porto-Carrero (3 jan. 1932) dava notícias sobre o funcionamento da Sociedade: "A atividade da Sociedade tem sido pequena... Entretanto, não têm estado inativos os psicanalistas - Marcondes, em São Paulo, Ayrosa e eu, aqui". Além disso, Porto-Carrero chamava a atenção para o fato de que o número de interessados crescia: "faz-se propaganda pelo ensino, principalmente. Na semana antialcoólica, Ayrosa 
levou a psicanálise à Sociedade de Medicina. Por mim, na Faculdade de Direito, em ambos os meus cursos, fiz farta derrama de conhecimentos psicanalíticos" (Porto-Carrero, 3 jan. 1932).

A perspectiva de que se alcançavam os objetivos desejados, incluindo a inserção da psicanálise no meio científico, se fazia cada vez mais presente nos psiquiatraspsicanalistas: "Por aqui, passo a passo, a psicanálise vem impregnando a psiquiatria oficial e conquistando os espíritos hesitantes ou emperrados" (Porto-Carrero, 3 jan. 1932). Por isso, a necessidade e o desejo de colaboração entre eles se faziam mais e mais imprescindíveis, como mostra o seguinte pedido de Porto-Carrero a Arthur Ramos: “Aqui estamos, e estou eu em particular, para auxiliá-lo no que lhe for útil. Em troca, mande-nos colaboração - se possível, urgente - para o $2^{\circ}$ número da Revista" (Porto-Carrero, 3 jan. 1932). Infelizmente, esse segundo número não chegaria a ser publicado.

O que chama mais atenção na carta de 1932, porém, é a preocupação dos membros da Sociedade Brasileira de Psicanálise com a tradução dos termos psicanalíticos e dos ensaios completos de Freud:

Mando um pouco da nomenclatura psicanalítica, conforme foi fixado pela nossa Sociedade Brasileira de Psicanálise. Verá que alguns termos de tradução incerta foram firmados, a meu ver, com acerto. Devo dizer-lhe com franqueza que me repugna muito o 'transferir', pois que 'transferência' traduz bem Übertragung. Outro termo, que na nossa nomenclatura recebeu tradução diversa da que a psicanálise emprega, é trieb. Traduzimola por 'impulso'. O francês possui apenas impulsion e poussé, aquela já empregada para significar a impulsão mórbida dos neuróticos coactos [neurose obsessiva], esta com o significado de 'surto' ou 'empuxo'; essa é a razão, parece-me, por que adotaram os franceses o neologismo pulsion; quanto a nós, porém, não estamos nesse impasse: de treiben, impeliu, triebe, impulso. Evidentemente, traduzir por instinto seria imprudente. Não sei se lhe agradará a nomenclatura da Sociedade; gostaria de ter o seu juízo (PortoCarrero, 3 jan. 1932).

Essa preocupação era tão grande que, anexo à carta, Porto-Carrero remetia traduções dos termos do alemão para o português, estabelecidas pela Sociedade Brasileira de Psicanálise:

Nomenclatura psicanalítica da Sociedade Brasileira de Psicanálise:

Pychoanalyse $=$ psicanálise

$I c h=$ Ego

Es $=I d$

$\ddot{U}$ ber-Ich $=$ Superego

Trieb $=$ impulso

Verdrängugn = recalcamento

Unterdrückung $=$ repressão

Verschiebung $=$ deslocamento

Übertragung = transferência

Fixierung = fixação

Gegenbesetzung = contracarga

Libidinös = libidinal

Isolierung $=$ isolamento

Ungeschehenmachen = cancelar, cancelamento

Angstneurose $=$ neurose de angústia 


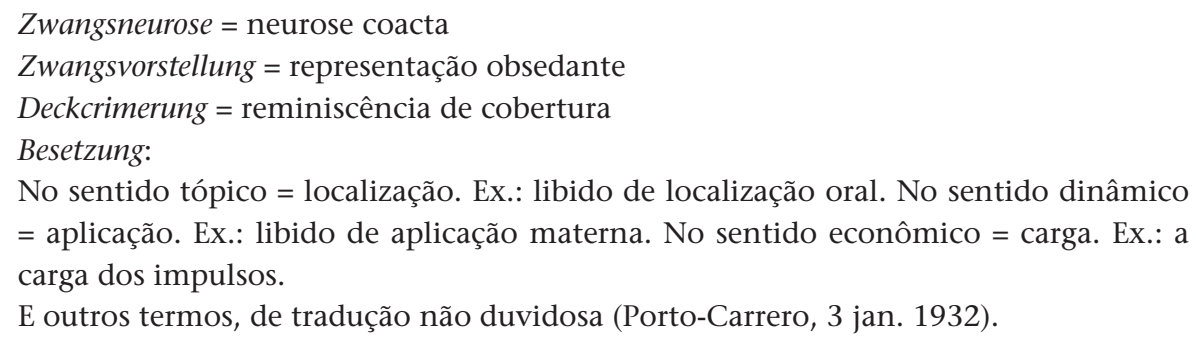

Essas definições eram de extrema importância, porque foram alguns dos membros ligados à Sociedade Brasileira de Psicanálise que traduziram os primeiros textos de Freud para o português. Além disso, era importante que se estabelecessem critérios de tradução das obras a fim de que elas se mantivessem em consonância com as "obras originais" de Freud. No ano de 1931, Durval Marcondes e Barbosa Corrêa publicariam a primeira tradução para o português de um texto freudiano: tratava-se de Cinco ensaios de psicanálise, lançado pela Editora Nacional de São Paulo (Oliveira, 2011, p.12). Marcondes enviaria a Freud sua tradução, recebendo um cartão com os dizeres: "Recebi sua tradução. A primeira no idioma português" (citado em Nosek et al., 1994, p.104). Além de Freud, também Max Eitingon retornaria a Marcondes: "Meus sinceros, embora atrasados, agradecimentos pela sua amabilidade em me enviar a sua tradução das cinco conferências do prof. Freud" (citado em Nosek et al., 1994, p.104).

Ao longo dos primeiros anos da década de 1930, um grupo dedicou-se ao trabalho de tradução de algumas obras de Freud, que foram publicadas pela editora carioca Guanabara/ Waissman-Koogan. Entre os tradutores estavam Odilon Gallotti, Elias Davidovitch, Isaac Izecksohn, Gladstone Parente, Porto-Carrero e Moysés Gikovate (Oliveira, 2002, p.7). De acordo com a pesquisadora Denise Bottmann (2014), nessa época, a Sociedade Brasileira de Psicanálise concebeu e deu início ao projeto de traduzir as obras de Freud, tarefa realizada principalmente a partir do francês e do espanhol. De acordo com ela, os seguintes títulos foram lançados:

1933 - Psychopathologia da vida quotidiana, trad. Elias Davidovitch; 1934 - Introdução à psicanálise, trad. Elias Davidovitch; Totem e tabu, "traducção directa do allemão", anônima, revista por J.P. Porto-Carrero; O futuro de uma ilusão (Psicanálise das religiões), trad. J.P. Porto-Carrero; Psicanálise e psiconeuroses, trad. Odilon Gallotti; Técnica psicanalítica e psicologia da angústia, trad. Odilon Gallotti; Psicologia da vida erótica, trad. Moysés Gikovate; Observações clínicas, trad. Elias Davidovitch, ed. Atlântida; Minha vida e a psicanálise, constando apenas "tradução autorizada", ed. Atlântida; Pensamentos sobre guerra e morte e O múltiplo interesse da psicanálise, ed. Machado e Ninitch; 1935 Interpretação dos sonhos e outros ensaios, trad. Odilon Gallotti; Introdução ao estudo dos sonhos; Sexualidade, trad. portuguesa de Osório de Oliveira, ed. Civilização Brasileira (Bottmann, 2014, p.160-162).

Ainda segundo Bottmann (2014, p.165), esse projeto da Sociedade Brasileira de Psicanálise para a tradução e publicação das obras completas de Freud foi interrompido após 1935, sendo retomado apenas em 1950 pela Editora Delta, quando o médico Elias Davidovitch encabeçou e coordenou a coleção. 


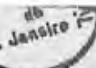

$$
\text { Rio, } 3.1 .932
$$

Cavo college de. Arther, tamss.

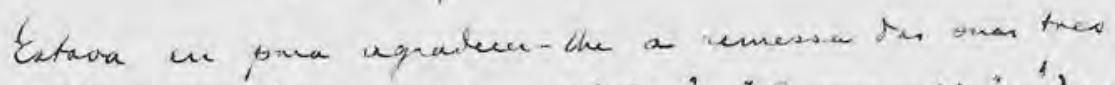

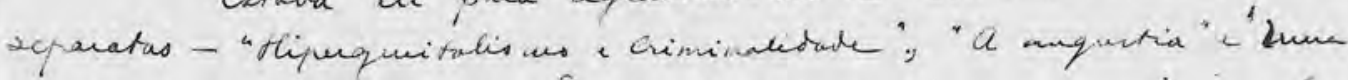

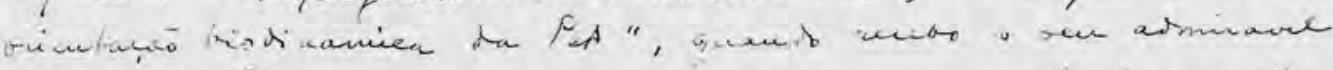

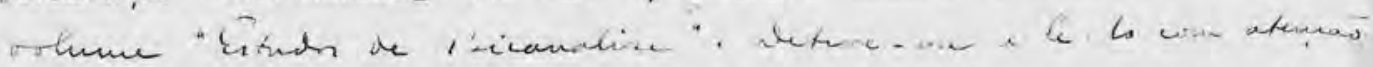

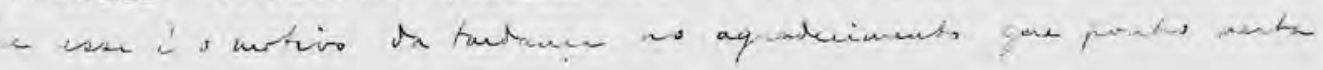
coutif

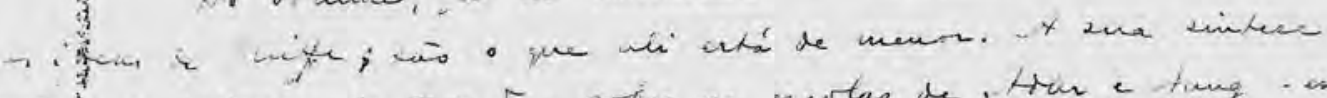

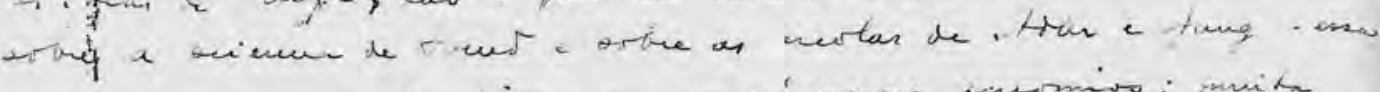

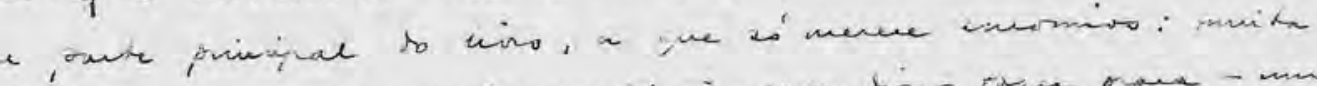

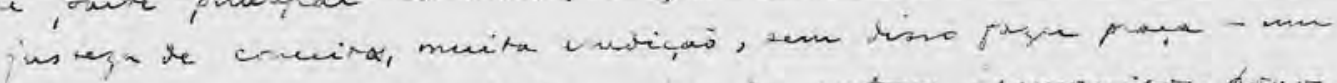

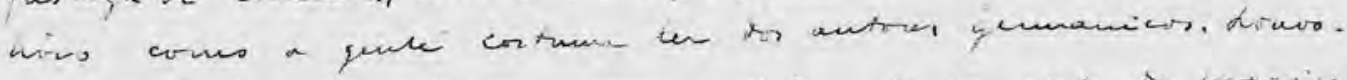

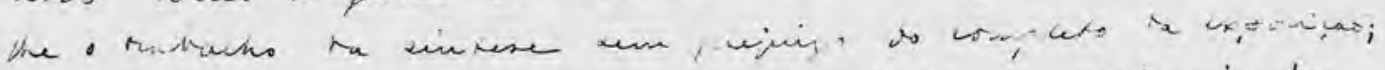

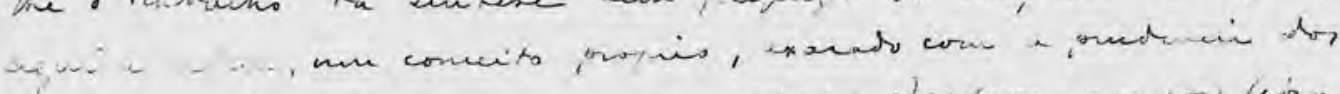

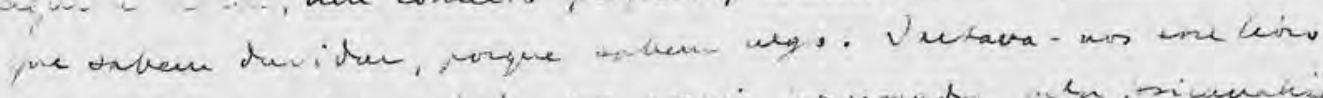

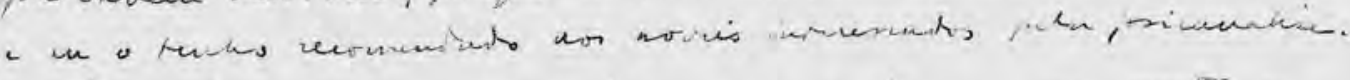

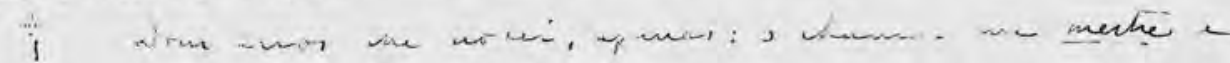

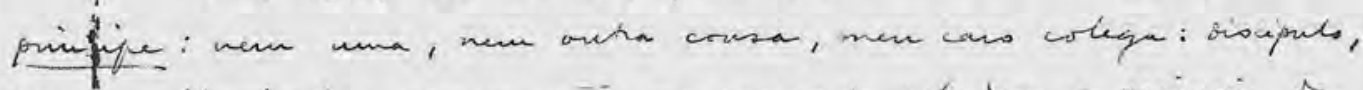

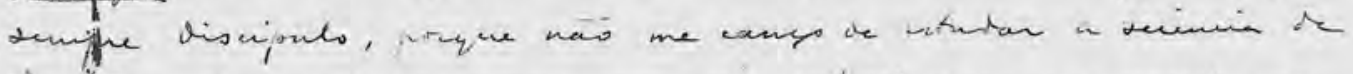

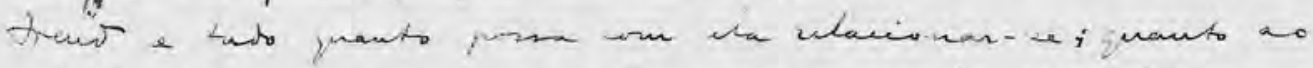

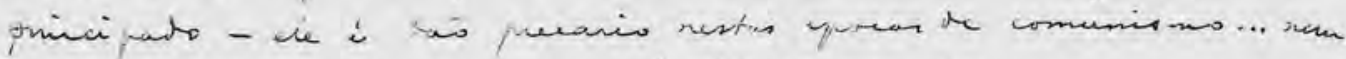

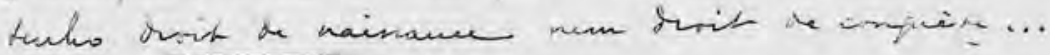

Junto the mousto wer suhs da nomentature pricana-

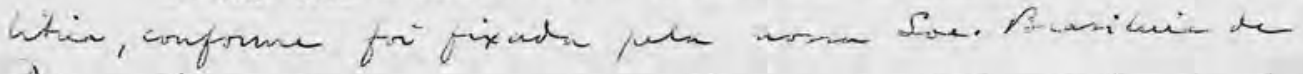

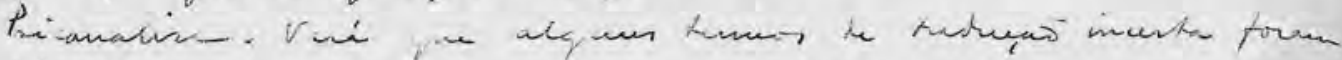

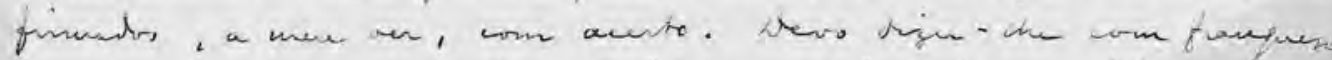

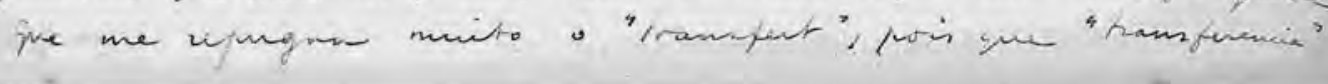

Carta de Julio Porto-Carrero a Arthur Ramos, p.1 (Biblioteca Nacional, Coleção Arthur Ramos) 


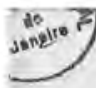

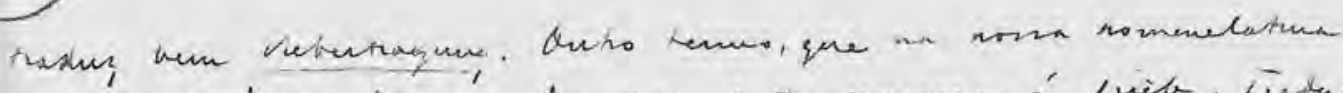

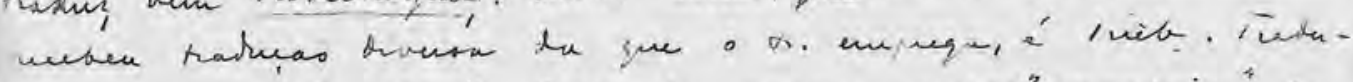

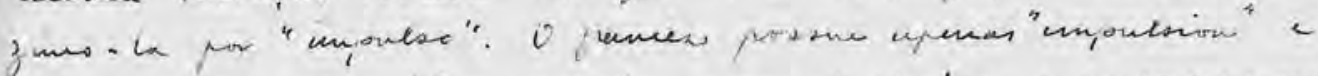

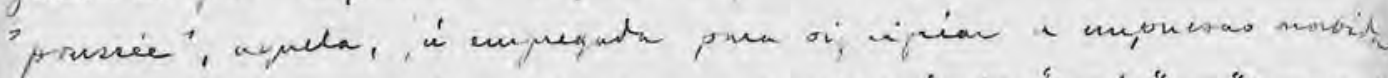

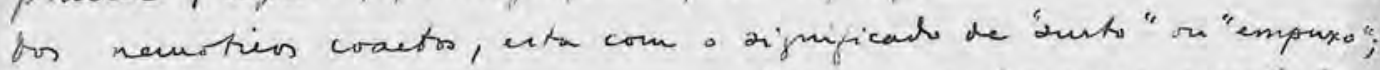

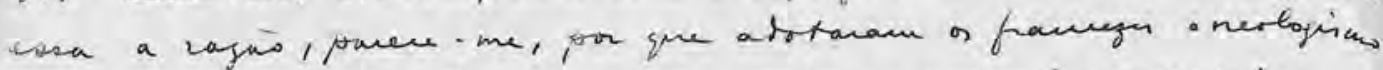

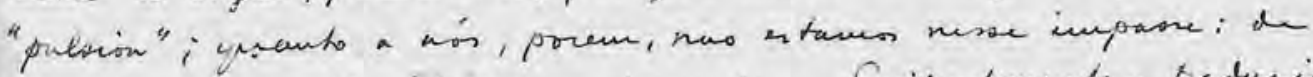

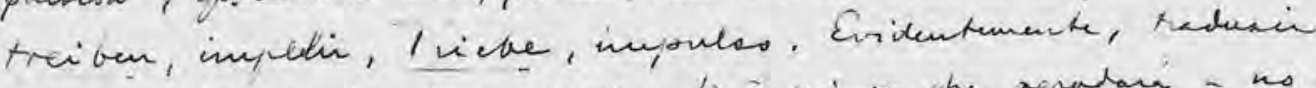

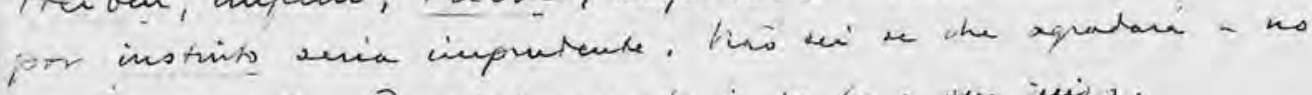

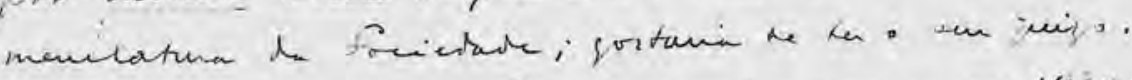

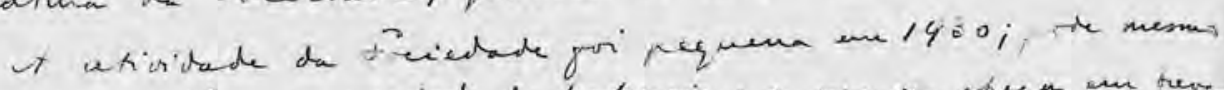

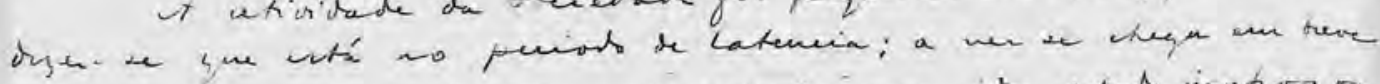

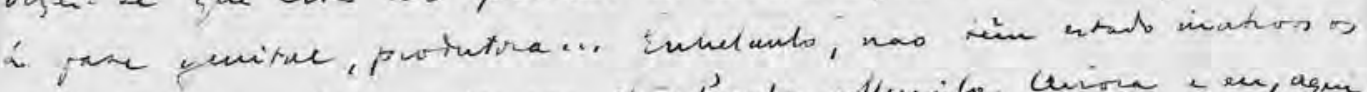

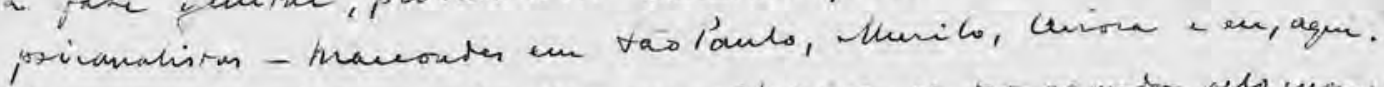

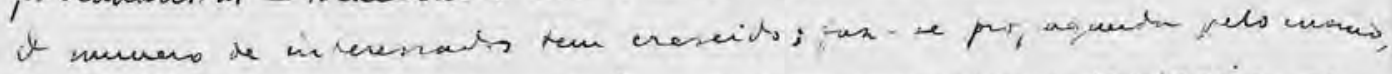

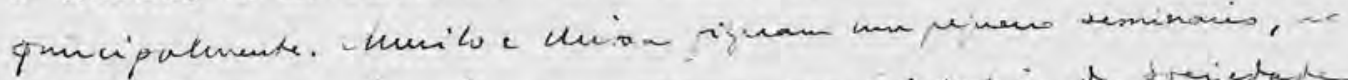

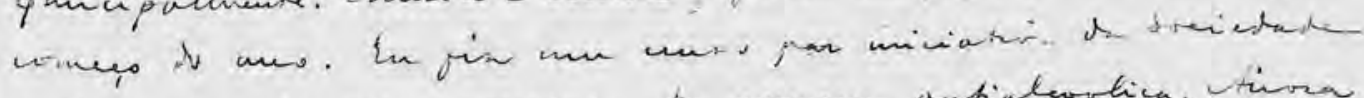

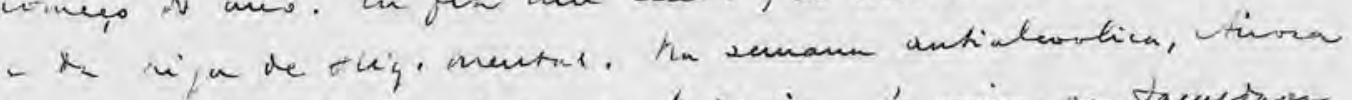

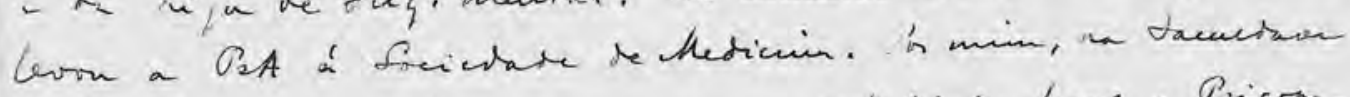

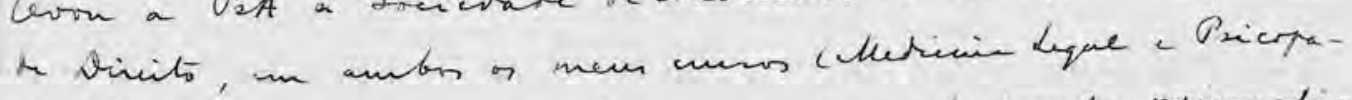

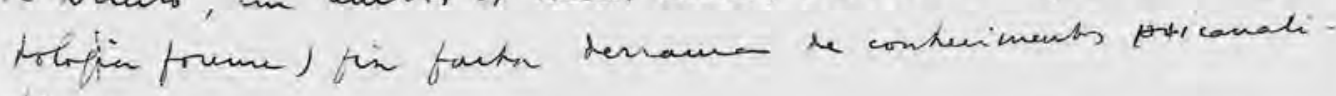
tions.

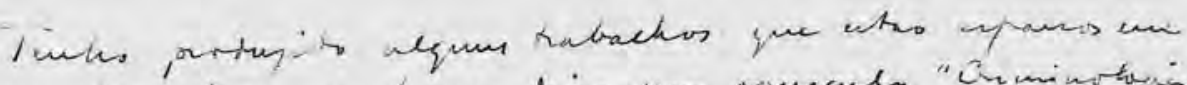

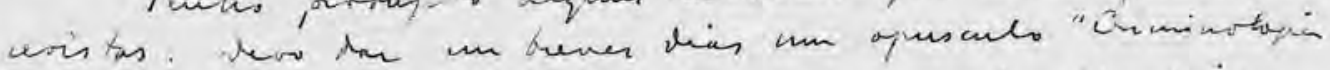

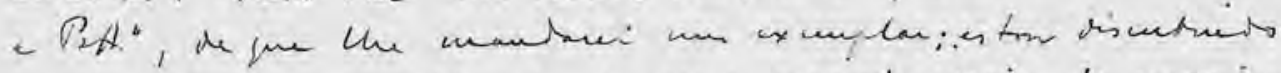

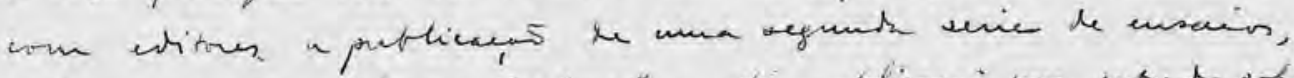

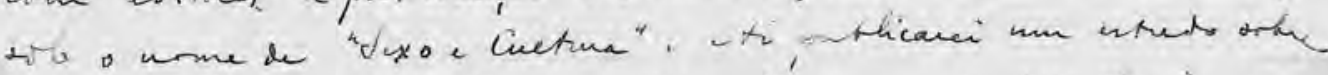

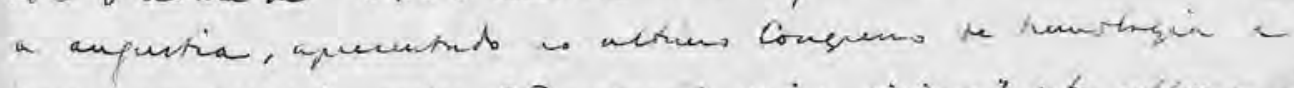

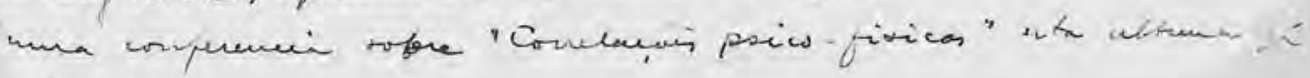
gantisath

Carta de Julio Porto-Carrero a Arthur Ramos, p.2 (Biblioteca Nacional, Coleção Arthur Ramos) 
$3 \mathrm{P}$

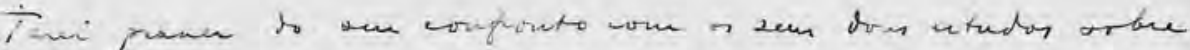

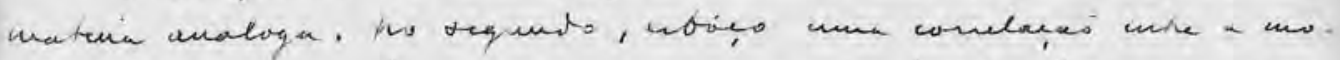

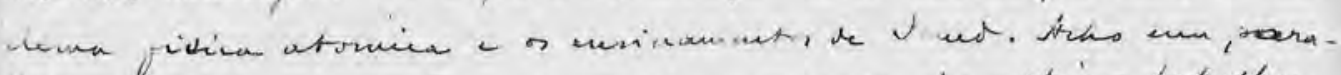

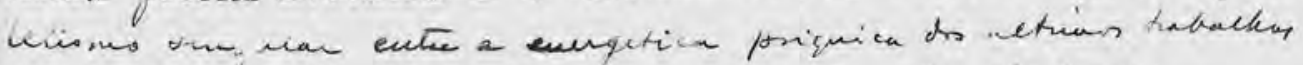

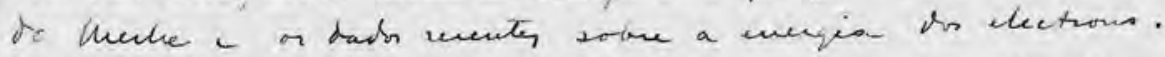

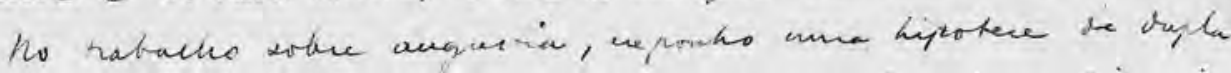

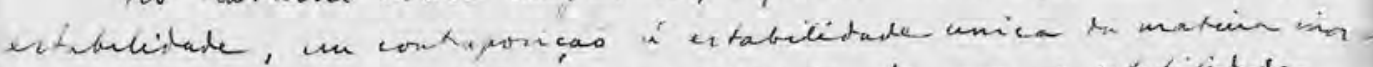

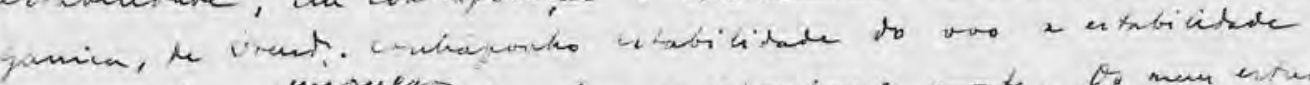

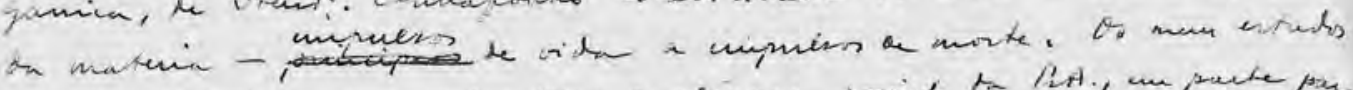

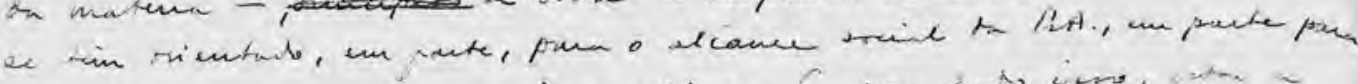

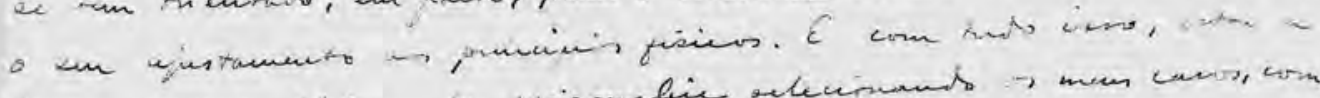

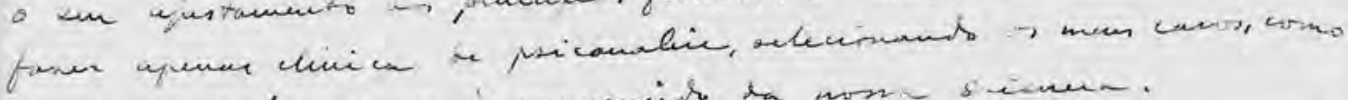

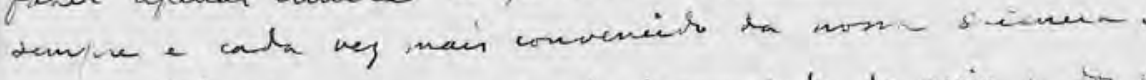

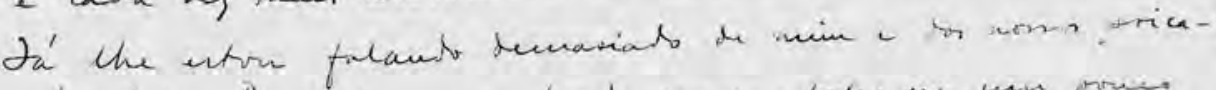

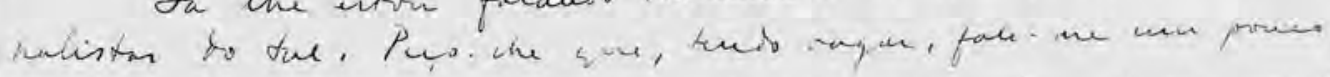

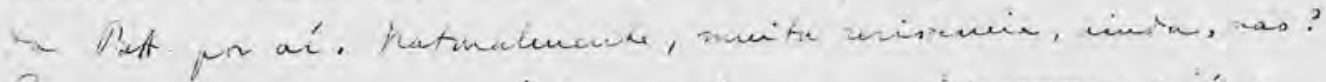

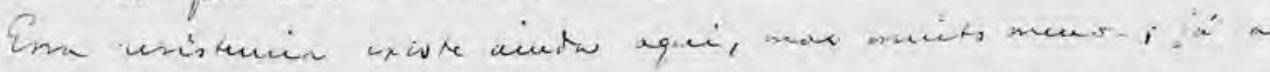

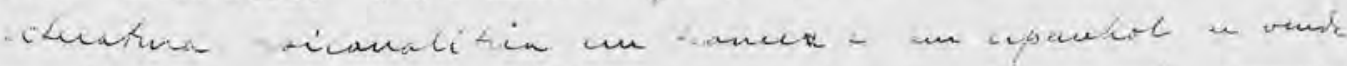

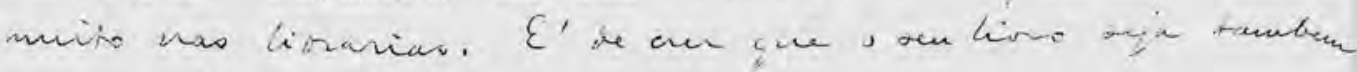
iqui mik, lite.

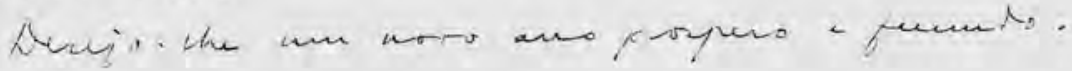

$$
\begin{aligned}
& \text { Cleix.me truave dew }
\end{aligned}
$$

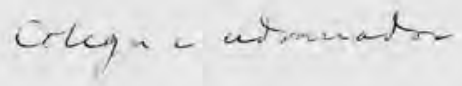$$
\text { Dortstureses }
$$

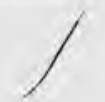

$$
\begin{aligned}
& \text { 12. I re sciubs } 72 \ldots= \\
& \text { res }
\end{aligned}
$$

Carta de Julio Porto-Carrero a Arthur Ramos, p.3 (Biblioteca Nacional, Coleção Arthur Ramos) 


\section{$\frac{\text { homenclatima Picanalítica }}{\text { de }}$ \\ Sie. Bras. de Pat}

Peyphocunalyse Pricanálise.

$\sqrt{\text { ch }}=E_{\text {gov. }}$

$\overline{\varepsilon_{s}}=s \alpha$

Über-2ch $=$ Supu-Ego.

Triet $=$ dmpontso

Mirtánoung - Recalcuments

Untersrückung - Repressas

Verschiebung - Austocamento

Übertragung I cansperemia

Dixierno vixaya

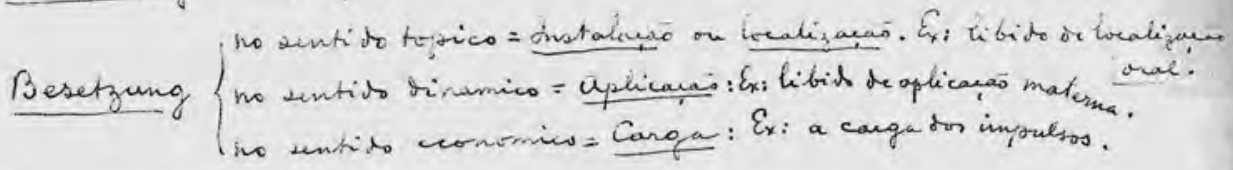

Eeganbersetzung - Contracaropa.

Sibidinos = livitinat.

Sorticunng = insulamento

Unogachehemmachen $=$ Cancelar, cancelamento

Arog tineurose $=$ heurose te angustia

Zuvangsnemose = hemese coacto

Luangrvastiting $=$ Repuesentivas obsidente

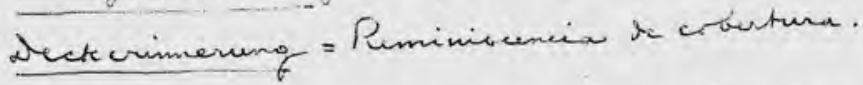

- E outroo temen, de tratuea nas duvidoza:
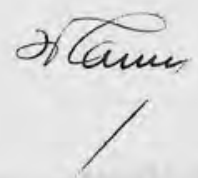

Carta de Julio Porto-Carrero a Arthur Ramos, p.4 (Biblioteca Nacional, Coleção Arthur Ramos) 


\section{Considerações finais}

Gostaríamos de chamar atenção, com a divulgação de tal correspondência, não é para a verificação de uma tradução "verdadeira", "correta" e/ou "adequada" de determinado conceito original de Freud (que, como vimos, foi uma preocupação da Sociedade de Brasileira de Psicanálise), mas sim para uma leitura e recepção específicas com as quais os psiquiatras se apropriavam da teoria (Facchinetti, 2012, p.60). Como vimos, a institucionalização da psicanálise no Rio de Janeiro se consolidou durante a década de 1930, rendendo frutos diretos de sua inserção no meio médico e científico do período.

O grupo dos psiquiatras-psicanalistas conquistou adeptos, discípulos, disseminando e lecionando tal saber em congressos, nas faculdades em que eram professores, nas diversas sociedades das quais fizeram parte. Como desdobramento da trajetória da teoria psicanalítica no Rio de Janeiro, nas décadas de 1920 e 1930, os psiquiatras-psicanalistas não tentariam institucionalizar a psicanálise aos moldes da IPA, nem buscariam a formação profissional ao seu modelo. Ao contrário, eles consolidariam a formação em psicanálise dentro da Faculdade de Medicina da Universidade do Rio de Janeiro, por meio de uma especialização em psicanálise (Castro, 2014).

\section{NOTAS}

${ }^{1}$ O médico Julio Pires Porto-Carrero (1887-1937), após se formar na Faculdade de Medicina do Rio de Janeiro em 1910, manteve sua prática no Hospital Nacional de Psicopatas, onde muito provavelmente teve contato com a obra de Freud, por intermédio de Juliano Moreira, Henrique Roxo e/ou Antonio Austregésilo, que a divulgaram no período. Porto-Carrero dizia ler Freud desde 1918, quando também chegou a debater com Afrânio Peixoto sobre a psicanálise: "Trocamos argumentos, ele discretamente contrário, eu timidamente favorável. A teoria do inconsciente era-me sedutora. E daí empreendi o estudo da psicanálise, que pouco a pouco, através da experiência, veio a ganhar-me de todo" (Porto-Carrero, 2002, p.155). Especificamente sobre a relação de Porto-Carrero com a psicanálise, ver Castro (2012).

${ }^{2}$ Arthur Ramos de Araújo Pereira (1903-1949) formou-se pela Faculdade de Medicina da Bahia em 1926 com tese de doutorado, defendida aos 23 anos de idade e publicada no mesmo ano pela Imprensa Oficial do Estado da Bahia sob o título Primitivo e loucura, na qual se inspirava nos estudos de Levy-Brühl, Freud e Jung. Ainda na Bahia, redigiu os seus Estudos de psicanálise em 1931, Freud, Adler e Jung e Psiquiatria e psicanálise em 1933. Em 1934 fixou-se no Rio de Janeiro e passou a dirigir a Seção Técnica de Ortofrenia e Higiene Mental do Departamento de Educação e Cultura do Distrito Federal. No mesmo ano, escreveu Educação e psicanálise, com base principalmente em Adler. Por essa época, lançou também Os furtos escolares (1939) e A criança problema (1939) (Penna, 2001).

${ }^{3}$ Sobre a organização, catalogação e disponibilização do acervo Arthur Ramos, ver Faillace (2004).

${ }^{4}$ Durval Ballegardi Marcondes (1899-1981) formou-se pela Faculdade de Medicina de São Paulo em 1924, com especialidade em psiquiatria. Juntamente com o psiquiatra Franco da Rocha, deu início, ainda na década de 1920, ao movimento psicanalítico paulista.

${ }^{5}$ Francisco Franco da Rocha (1864-1930) foi um renomado psiquiatra paulista. Na década de 1890, concebeu e administrou o Asilo de Alienados do Juquery e, a partir de 1901, sua colônia agrícola em São Paulo (Pacheco Filho, Antunes, 2001).

${ }^{6}$ Em carta remetida a Porto-Carrero em 1928, Freud solicitava um relatório afirmando que este poderia ser escrito "naturalmente em francês, se isto lhe é mais cômodo" (citado em Lago, 16 ago. 2011).

${ }^{7}$ Naquele congresso foi acordado que a formação psicanalítica, desenvolvida pelo Instituto Psicanalítico de Berlim, seria o modelo-padrão de formação para todas as sociedades pertencentes à Associação Psicanalítica Internacional, compreendendo a análise didática, o ensino teórico e o trabalho clínico supervisionado (Ponte, 1999, p.61-62). 


\section{REFERÊNCIAS}

BOTTMANN, Denise.

Curiosidades freudianas (1931-1969). Revista

Belas Infiéis, v.2, n.2, p.159-173. 2014.

CASTRO, Rafael Dias.

A sublimação do "id primitivo" em "ego civilizado": o projeto dos psiquiatras-psicanalistas para civilizar o Brasil. Tese (Doutorado) - Casa de Oswaldo Cruz, Fiocruz, Rio de Janeiro. 2014.

CASTRO, Rafael Dias.

Psicanálise e educação sexual na obra de Julio Porto-Carrero: Rio de Janeiro (décadas de 1920 e 1930). In: Mollo, Helena M. (Org.). Biografia e história das ciências: debates com a história da historiografia. v.1. Ouro Preto: Edufop. p.185202. 2012.

EDITORIAL.

Diário Carioca. 11 maio 1930.

\section{EDITORIAL.}

Revista Brasileira de Psicanálise, v.1, n.1, p.5. 1928.

\section{EDITORIAL.}

Correio da Manhã. 6 jul. 1928.

FACCHINETTI, Cristiana.

Psicanálise para brasileiros: história de sua circulação e sua apropriação no entre-guerras. Culturas Psi, v.1, n.1, p.45-62. 2012.

\section{FACCHINETTI, Cristiana.}

Deglutindo Freud: história da digestão do discurso psicanalítico no Brasil, 1920-1940. Tese (Doutorado) - Universidade Federal do Rio de Janeiro, Rio de Janeiro. 2001.

FAILLACE, Vera Lúcia (Org.).

Arquivo Arthur Ramos: inventário analítico. Rio de Janeiro: Fundação Biblioteca Nacional. 2004.

FIGUEIRÔA, Silvia Fernanda de Mendonça. Mundialização da ciência e respostas locais: sobre a institucionalização das ciências naturais no Brasil (de fins do século XVIII à transição ao século XX). Asclepio, v.50, n.2, p.107-123. 1998.

\section{FIOCRUZ.}

Fundação Oswaldo Cruz. Guia de fontes e catálogo de acervos e instituições para pesquisas em saúde mental e assistência psiquiátrica no Estado do Rio de Janeiro. Rio de Janeiro: Laps. 2004.

FREUD, Sigmund.

Carta a Arthur Ramos. Trad. Gertraud Fisch Cunha. Coleção Arthur Ramos; localização: 49,02,001 n.004 (Biblioteca Nacional, Rio de Janeiro). 1 jun. 1932.

LAGO, Pedro Corrêa do.

Freud descobre o Brasil. Disponível em: http:// revistapiaui.estadao.com.br/blogs/questoesmanuscritas/geral/freud-descobre-o-brasil. Acesso em: 5 jun. 2012. 16 ago. 2011.

NOSEK, Leopoldo et al.

Álbum de família: imagens, fontes e ideias da psicanálise em São Paulo. São Paulo: Casa do Psicólogo. 1994.

NOTICIÁRIO.

Sessão de Fundação da Sociedade Brasileira de Psicanálise, 24.11.1927. Revista Brasileira de Psicanálise, v.1, n.1. 1928.

OLIVEIRA, Carmen Montechi.

A recepção das ideias psicanalíticas no Brasil (1915-1937). Trabalho apresentado no 6. Congresso Brasileiro de Psicopatologia Fundamental, 2002. Recife. 2002.

OLIVEIRA, Cristiane.

A emergência histórica da sexualidade infantil no Brasil. Revista Epos, v.2, n.2. 2011.

PACHECO FILHO, Raul; ANTUNES, Mitsuko Aparecida.

Francisco Franco da Rocha. In: Campos, Regina Helena F. (Ed.). Dicionário biográfico da psicologia no Brasil. Rio de Janeiro: Imago. 2001.

PACHECO E SILVA, Antonio Carlos. A proteção aos insanos no Segundo Reinado. Revista de Psiquiatria Clínica, v.36, n.5, p.208-215. 2009.

PENNA, Antonio.

Arthur Ramos de Araújo Pereira. In: Campos, Regina Helena F. (Ed.). Dicionário biográfico da psicologia no Brasil. Rio de Janeiro: Imago. 2001.

PERESTRELLO, Marialzira.

Primeiros encontros com a psicanálise no Brasil (1899-1937): os precursores do movimento psicanalítico. In: Perestrello, Marialzira. Encontros: psicanálise. Rio de Janeiro: Imago. 1992.

PONTE, Carlos Fidelis.

Médicos, psicanalistas e loucos: uma contribuição à história da psicanálise no Brasil. Dissertação (Mestrado) - Escola Nacional de Saúde Pública, Fiocruz, Rio de Janeiro. 1999.

PORTO-CARRERO, Julio.

A contribuição brasileira à psicanálise [1929]. Revista Latinoamericana de Psicopatologia Fundamental, v.5, n.5. 2002.

PORTO-CARRERO, Julio.

Carta a Arthur Ramos. Coleção Arthur Ramos; localização: I-35,26,930 (Biblioteca Nacional, Rio de Janeiro). 3 jan. 1932. 
PORTO-CARRERO, Julio.

Carta a Arthur Ramos. Coleção Arthur Ramos; localização: I-35,26,929 (Biblioteca Nacional, Rio de Janeiro). 8 abr. 1929.

RAMOS, Arthur.

O movimento psicanalítico no Brasil. Bahia Medica, n.1, p.22-23. jan. 1933.
SAGAWA, Roberto.

Durval Marcondes e o movimento psicanalítico. In: Sagawa, Roberto. Redescobrir as psicanálises. São Paulo: Lemos Editorial. p.82-93. 1992.

VENANCIO, Ana Teresa.

As faces de Juliano Moreira: luzes e sombras sobre seu acervo pessoal e suas publicações. Estudos Históricos, v.2, n.36, p.59-73. 2005. 


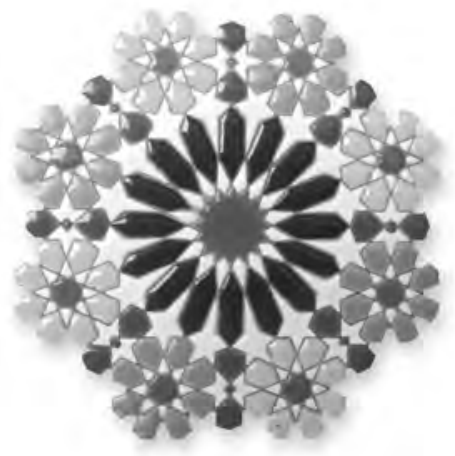

